\title{
Does harvesting of an internal thoracic artery with an ultrasonic scalpel have an effect on sternal perfusion?
}

Erman Pektok, MD, ${ }^{a}$ Mustafa Cikirikcioglu, MD, PhD, ${ }^{a}$ Cagatay Engin, MD, ${ }^{b}$ Gozde Daglioz, MD, ${ }^{\mathrm{c}}$ Zehra Ozcan, MD, ${ }^{\mathrm{C}}$ and Hakan Posacioglu, MD

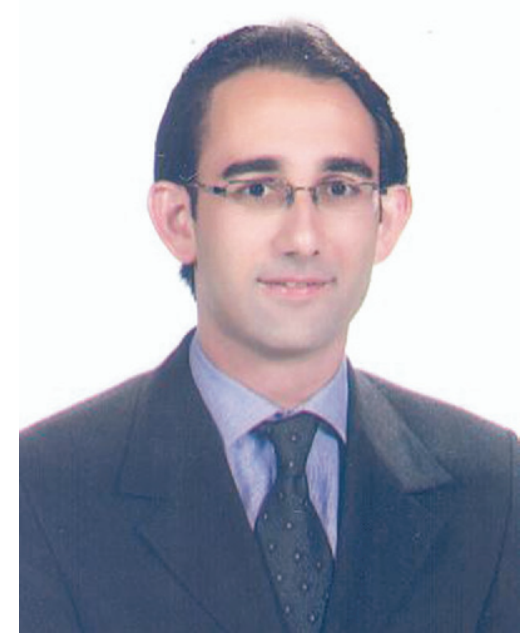

Dr Pektok
From the Service for Cardiovascular Surgery, University of Geneva, ${ }^{a}$ Geneva, Switzerland; and the Departments of Cardiovascular Surgery $^{\mathrm{b}}$ and Nuclear Medicine, ${ }^{\mathrm{c}}$ Ege University, Bornova-Izmir, Turkey.

Received for publication Nov 9, 2006; revisions received Jan 24, 2007; accepted for publication Jan 29, 2007.

Address for reprints: Erman Pektok, MD, Hôpitaux Universitaire de Genève, Service de Chirurgie Cardiovasculaire, Rue Michelidu-Crest 24, CH-1211 Genève 14, Switzerland (E-mail: epektok@ hotmail.com).

J Thorac Cardiovasc Surg 2007;134:442-7

$0022-5223 / \$ 32.00$

Copyright $\odot 2007$ by The American Association for Thoracic Surgery

doi:10.1016/j.jtcvs.2007.01.079
Objectives: Despite many animal and clinical studies to date, there is still debate on the effect of internal thoracic artery harvesting on postoperative sternal perfusion and thus healing. We performed a prospective clinical study to assess the postoperative sternal perfusion in patients who underwent surgical coronary revascularization by means of unilateral internal thoracic artery harvesting and to evaluate the effect of 2 harvesting methods, namely electrocautery and use of an ultrasonic scalpel.

Methods: Between November 2004 and March 2005, 30 consecutive patients (25 male patients; age, $58.34 \pm 9.42$ years; mean New York Heart Association class, $1.90 \pm 0.76)$ scheduled for conventional coronary surgery were enrolled in this study. After obtaining informed consent, they were randomized into 2 groups. The left internal thoracic artery was harvested as a pedicle graft in all patients by using the corresponding method. All patients underwent $99 \mathrm{mTc}-$ methylene diphosphonate bone scintigraphy preoperatively to evaluate baseline sternal perfusion. Control scintigraphy was performed on postoperative day 7 .

Results: Sternal perfusion showed a significant increase on postoperative scans compared with that at baseline (1067 \pm 191 counts/pixel vs $919 \pm 102$ counts/pixel for the right half, $P<.001 ; 1064 \pm 179$ counts/pixel vs $905 \pm 107$ counts/pixel for the left half, $P<.001)$. There was no significant difference between the right and left sternal halves postoperatively. The method used for harvest had no significant effect on postoperative sternal perfusion (electrocautery $=1037 \pm 121 \mathrm{counts} /$ pixel vs scalpel $=1097 \pm 109$ counts/pixel for the right half, $P>.05$; electrocautery $=$ $1040 \pm 126$ counts/pixel vs scalpel $=1089 \pm 130$ counts/pixel for the left half, $P$ $>.05)$.

Conclusions: Sternal perfusion increases soon after coronary bypass surgery, probably as a consequence of the healing process, but the source of perfusion for harvest side remains unclear. Harvesting of internal thoracic arteries with an ultrasonic scalpel has no advantageous effects on postoperative sternal perfusion.

$\mathrm{F}$ Tor decades, internal thoracic artery (ITA) grafts have been the most popular autologous arterial grafts for the revascularization of hearts in ischemic heart disease. ${ }^{1}$ Higher patency rates compared with those of autologous saphenous vein grafts ( $83 \%-95 \%$ vs $50 \%-60 \%$ for 10 years) and resistance to atherosclerosis are the major advantages of ITA grafts. ${ }^{2,3}$ However, the ITA is the major blood supply for the sternum through the periosteal plexus formed by its segmental branches. ${ }^{4}$ Results of various experimental ${ }^{5,6}$ and clinical ${ }^{7}$ studies support these data. A major factor of wound healing is adequate blood supply. Bilateral harvest of ITAs for the revascularization of coronary arteries might result in total devascularization of sternum ${ }^{4}$ and thus delay healing. Increased rates of sternal dehiscence after coronary revascularization with bilateral ITAs $(1.1 \%, 2.3 \%$, and $8.5 \%$ for no 


\section{Abbreviations and Acronyms \\ $\mathrm{CABG}=$ coronary artery bypass graft \\ ITA $=$ internal thoracic artery \\ ROI = region of interest \\ USS = ultrasonic scalpel}

ITA, unilateral ITA, and bilateral ITA groups, respectively), ${ }^{8}$ might emphasize the effect of sternal blood supply after coronary bypass surgery. Collateral blood flow through posterior intercostal arteries and pectoral branches of the thoracoacromial axis might have a role in the sternal healing process after bilateral harvest of ITAs. ${ }^{9-11}$

To date, numerous studies have been published on sternal blood flow after sternotomy, ITA harvest, or both. .7,12-17 $^{-17}$ Initial studies focused on the role of ITAs and their branches on sternal blood supply. Recently, consensus has been achieved among the authors that skeletonization of ITA grafts has advantageous effects on postoperative sternal perfusion. ${ }^{6,13,18,19}$ Electrocautery has been used as a method of choice for ITA harvest in conventional operations. The ultrasonic scalpel (USS) is a relatively novel device developed to eliminate the potential risks of electrical injury on the tissues. It has been widely used for harvesting the radial artery conduits. ${ }^{20,21}$ The major advantages of this method were less thermal injury and necrotic features at the resection rim in a lung resection model, ${ }^{22}$ less endothelial damage in ITA grafts, ${ }^{23}$ and reduced vasospastic response of the arterial wall. ${ }^{20}$ Nevertheless, no study has been published yet evaluating the effects of the USS on sternal perfusion after ITA harvest in comparison with electrocautery.

The aim of this study was to monitor the sternal perfusion 7 days after ITA pedicle harvest, as well as to evaluate the effects of the USS technique on sternal perfusion in the early postoperative follow-up period in comparison with use of electrocautery. ITA grafts were harvested as pedicles in all cases to obtain 2 comparable groups and to avoid the effect of the skeletonization technique.

\section{Materials and Methods}

Thirty consecutive patients (25 male patients; mean age, $58.34 \pm$ 9.42 years; mean New York Heart Association class, $1.90 \pm 0.76$ ) scheduled for conventional coronary artery bypass grafting $(\mathrm{CABG})$ surgery were enrolled in this prospective randomized study between November 2004 and March 2005. Inclusion criteria were age of less than 75 years, isolated primary coronary artery disease, elective bypass surgery, and a left ventricular ejection fraction of greater than $30 \%$. Patients who had a history or diagnosis of diabetes mellitus, previous sternotomy and/or thoracotomy, previous major thoracic trauma, malignant disease, radiotherapy and/or chemotherapy, major vascular (abdominal aortic, iliac, and/or femoral arterial) disease, and hematologic disease were excluded. After providing informed consent, they were ran- domized into 2 groups: the electrocautery group and the USS group. The right sternal halves were left intact in both groups and served as controls.

\section{Perioperative Protocol}

Routine preparation was performed, including physical examination, routine blood tests, echocardiography, and coronary angiography.

Under elective conditions and after achievement of standard general anesthesia, a median sternotomy was performed with a pneumatic saw in the conventional fashion. After the median sternotomy, the left ITA was harvested as a $2-\mathrm{cm}$ pedicle, including the artery, accompanying veins, muscle, and fascia, by using electrocautery (25 W; Aspen Sabre Electrosurgical Unit, Con Med) or a USS (Harmonic Scalpel; Ultracision, Inc; 5-mm twisted edge, HC 145, Level III) on identical settings according to the group in which the patient was randomized. No effort was spent to preserve the lateral musculophrenic-superior epigastric bifurcation. After aorto-right atrial cannulation, aortocoronary bypass grafting under moderate hypothermia and cardiopulmonary bypass was performed for coronary arteries other than the left anterior descending coronary artery by using the great saphenous vein grafts, if indicated. Left ITA-left anterior descending coronary artery anastomosis was performed while rewarming. At the end, hemostasis of the left ITA bed was performed by using the corresponding device, liga-clips (Ligaclip LT200, Ethicon), and the sternum was closed with separate steel wires. Median sternotomy, harvest of grafts, and hemostasis were performed by one surgeon (E.P.) in all cases.

\section{Radionuclide Imaging}

Two or 3 days before the operation, all patients underwent bone scintigraphy to evaluate the baseline sternal perfusion. Three hours after the intravenous injection of radioactively marked $15-$ to 20-mCi (540-740 MBq) 99mTc-methylene diphosphonate, static images were obtained with a single-detector gamma camera (Sophy DSX) equipped with a general-purpose collimator. Sternal activity in the anterior thoracic views was calculated quantitatively by using the region of interest (ROI) program. Six ROIs were obtained for each sternum by dividing the sternum into manubrium, corpus, and xyphiod process craniocaudally and by dividing each zone into 2 halves as mirror images on each half of the sternum. For each ROI, the number of counts per pixel was calculated by our nuclear medicine specialists (G.D., Z.O.), who were blinded to group allocation. For each sternal half, sternal activity was calculated as the sum of its 3 ROIs.

Repeat tests with the same techniques were performed $6.93 \pm$ 0.69 days after the operation $(6.80 \pm 0.56$ days in the electrocautery group and $7.07 \pm 0.07$ days in the USS group, $P>.05$ ). All patients were also evaluated by means of physical examination on postoperative days 14 and 30 in the clinic.

\section{Statistical Analysis}

SPSS for Windows 13.0 software (SPSS, Inc) was used for statistical analysis. The data are presented as means \pm standard deviations for continuous numbers, percentages, or both for parametric variables. The $\chi^{2}$ test was used to compare parametric variables. The Mann-Whitney $U$ test was used to compare nonmatched and 
TABLE 1. Preoperative patient characteristics

\begin{tabular}{lccc}
\hline & $\begin{array}{c}\text { EC group } \\
(\mathbf{n}=\mathbf{1 5})\end{array}$ & $\begin{array}{c}\text { USS group } \\
(\mathbf{n}=\mathbf{1 5})\end{array}$ & $\boldsymbol{P}$ value \\
\hline Age (y) & $59.5 \pm 9.2$ & $57.2 \pm 9.9$ & .5 \\
Sex (female/male) & $2 / 13$ & $3 / 12$ & .6 \\
Body surface area (m $\left.{ }^{2}\right)$ & $1.9 \pm 0.1$ & $1.8 \pm 0.2$ & .7 \\
Preoperative NYHA class & $1.9 \pm 0.7$ & $1.9 \pm 0.8$ & .9 \\
Preoperative LVEF (\%) & $53.9 \pm 10.5$ & $51.2 \pm 11.4$ & .5 \\
Hypertension & 5 & 7 & .5 \\
COPD & 0 & 1 & .3 \\
\hline
\end{tabular}

EC, Electrocautery; USS, ultrasonic scalpel; NYHA, New York Heart Association; $L V E F$, Left ventricular ejection fraction; $C O P D$, chronic obstructive pulmonary disease.

nonparametric values. Matched nonparametric values were compared with the Wilcoxon paired test.

\section{Results}

The 2 groups were comparable with respect to preoperative characteristics and perioperative data (Tables 1 and 2). Preoperative sternal perfusion was comparable for each corresponding ROI between the left and right halves of both groups. Likewise, all corresponding ROIs were comparable between the 2 groups in preoperative tests (Figure 1). Sternal perfusion was found to decrease significantly when comparing distal versus proximal sternal areas (ie, corpus vs manubrium, xiphoid process vs corpus, and xiphoid process vs manubrium), indicating that the xiphoid process is the poorest part of the sternum for blood supply.

In the postoperative scans, both groups have shown an increased uptake in all ROIs on both sides, ranging between $10.12 \%$ and $21.36 \%$. This increase in all ROIs, except RMI in the USS group, was significant (Figure 1). However, no significant difference was found between the 2 groups regarding the postoperative sternal perfusion and between the left and right halves in both groups.

Concerning all patients, sternal perfusion showed an increase of $16.10 \%$ (919 \pm 102 counts/pixel to $1067 \pm 191$ counts/pixel, $P<.001$ ) on the right (no harvest) half and a $17.57 \%$ increase $(905 \pm 107$ counts/pixel to $1064 \pm 179$ counts/pixel, $P<.001$ ) on the left (harvest) half 7 days after surgical intervention with respect to preoperative values (Figure 2). Left and right sternal perfusion was found to be similar on the postoperative tests $(1064 \pm 179$ counts/pixel vs $1067 \pm 191$ counts/pixel, respectively; $P>.05$ ).

Sternal dehiscence was observed in one patient in each group, and complete sternal healing was achieved by using conservative therapy in both patients within 30 days after the operation. No sternal wound infection or mediastinitis had developed. Postoperative characteristics (intubation time, drainage, sternal dehiscence, inotropic support, intraaortic balloon pump use, low cardiac output, arrhythmia,
TABLE 2. Perioperative data

\begin{tabular}{lccc}
\hline & $\begin{array}{c}\text { EC group } \\
\text { (n = 15) }\end{array}$ & $\begin{array}{c}\text { USS group } \\
\text { (n = 15) }\end{array}$ & $\boldsymbol{P}$ value \\
\hline No. of grafts per patient & $2.9 \pm 0.8$ & $3.0 \pm 1.0$ & .7 \\
CPB time (min) & $83.4 \pm 25.9$ & $80.9 \pm 28.4$ & .9 \\
Crossclamp time (min) & $50.3 \pm 17.2$ & $52.9 \pm 19.4$ & .5 \\
\hline
\end{tabular}

$E C$, Electrocautery; USS, ultrasonic scalpel; $C P B$, cardiopulmonary bypass.

resuscitation, intensive care unit stay, and in-hospital stay) were similar in the 2 groups (Table 3 ).

\section{Discussion}

Bone healing starts immediately after injury with the inflammatory response, and original structure and function is restored completely by time. Adequate blood supply is of great importance for bone healing from the beginning to the end. Sternotomy is a major trauma that has a potential risk for inadequate sternal healing and dehiscence after surgical intervention. Harvest of ITAs in patients undergoing CABG is an additional risk factor for inadequate healing after median sternotomy because the major blood supply for the sternum is used for revascularization. ${ }^{8}$

Because of technical and ethical considerations, no assessment of sternal blood flow could be performed either in the perioperative or the early postoperative periods in clinical studies. Our routine practice for timing of discharge for the patients without any complications after CABG surgery is postoperative day 7 or 8 , which permits a smooth recovery and rehabilitation period in the hospital. We decided to perform the control scintigraphy at postoperative day 7 to obtain the results of scintigraphy before discharge. Also, this time point gave us the opportunity to fill in the gap in the time course of early postoperative sternal perfusion in the literature.

The data obtained from the animal studies showed that sternotomy itself does not affect the sternal perfusion. ${ }^{5}$ However, sternal perfusion is reduced up to $85 \%$ to $90 \%$ immediately after the ITA harvest. ${ }^{5,6}$ Nevertheless, this reduction in sternal perfusion is reversible. Parish and associates $^{6}$ showed in a canine model that sternal perfusion was diminished $85.1 \%$ after pedicled ITA harvest with respect to baseline values $(P<.001)$, and a slight reperfusion was observed after closure of the sternum (78.3\% reduction with respect to baseline values, $P<.001$ ), proving a rapid mechanism to restore the perfusion immediately after the devascularization. In a clinical study 5 days after the operation, sternal perfusion was found to be $34 \%$ less than that of the preoperative values, ${ }^{13}$ indicating an increase of perfusion with respect to earlier postoperative values as well. In our study, 7 days after the operation, sternal perfusion was found to be restored, with an increase of $17.57 \%$ with respect to preoperative values for the harvest side. 

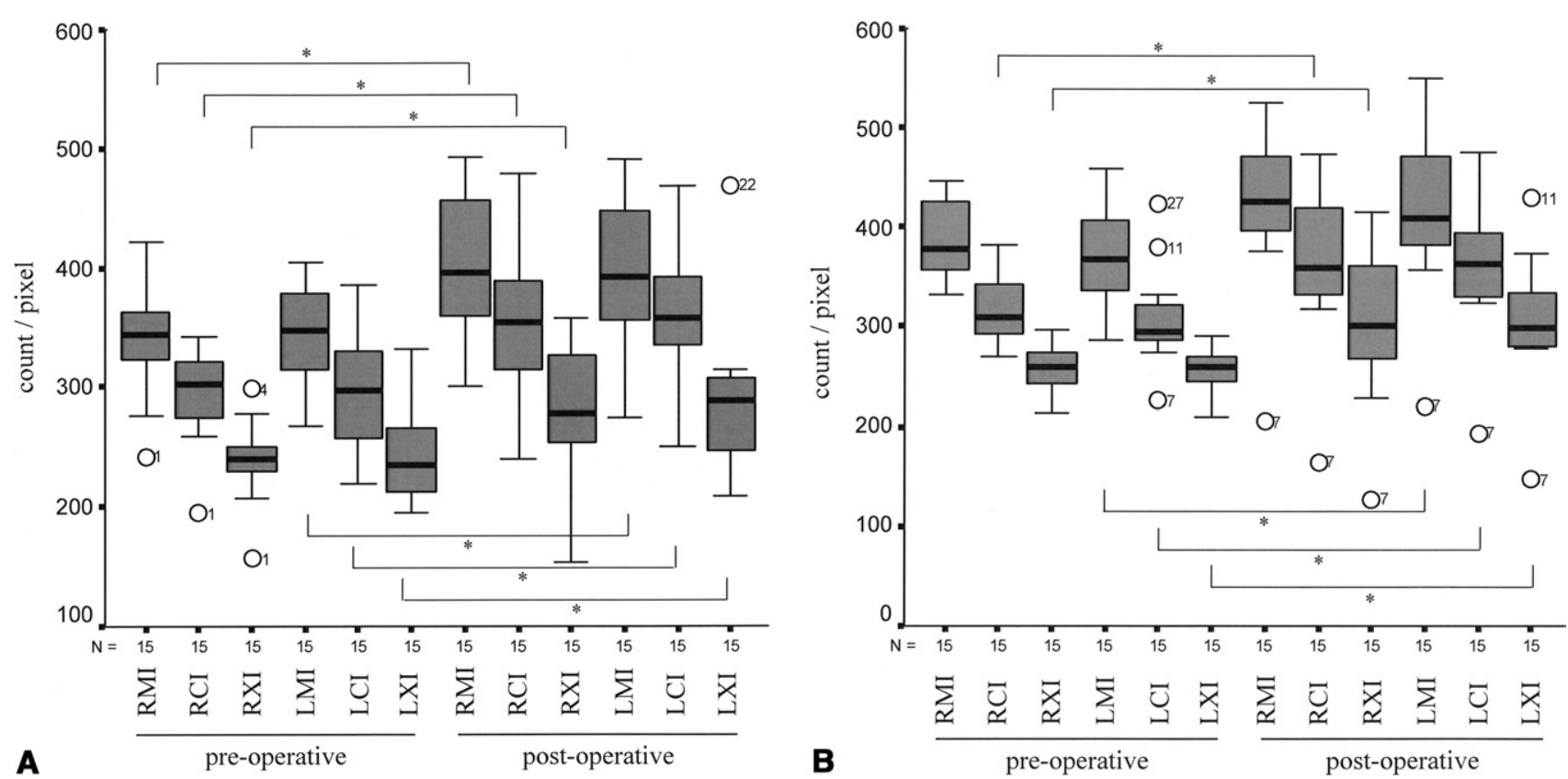

Figure 1. A, Sternal perfusion for the electrocautery group. The data obtained from preoperative and postoperative scintigraphies are shown in box-plot format. Open circles represent the patients' values out of $75 \%$ confines, and numbers represent the corresponding patient. $R$, Right; $L$, left; $M$, manubrium; $C$, corpus; $X$, xiphoid process; $I$, index. ${ }^{*} \boldsymbol{P}<.05$. B, Sternal perfusion for the ultrasonic scalpel group. The data obtained from preoperative and postoperative scintigraphies are shown in box-plot format. Open circles represent the patients' values out of $75 \%$ confines, and numbers represent the corresponding patient. $R$, Right; $L$, left; $M$, manubrium; $C$, corpus; $X$, xiphoid process; $I$, index. ${ }^{*} P<.05$.

Likewise, Korbmacher and associates ${ }^{14}$ reported an increase of $53 \%$ for the harvest side (47\% for manubrium, $65 \%$ for corpus, and $63 \%$ for xiphoid process) 12 days after the ITA harvest with a similar radionuclide imaging technique. Eighteen months after surgical intervention, perfusion was found to be similar to what it was before the operation. ${ }^{15}$ We can conclude that compensatory mechanisms occur soon after devascularization, and sternal perfusion is restored in the first week, but the complete healing process takes longer.

Our findings for the increase of sternal perfusion on the right (nonharvest) side is parallel to the results that Korbmacher and associates ${ }^{14}$ stated in their article. They reported a $63 \%$ increase in sternal perfusion on the right (nonharvest) side 12 days after surgical intervention in a similar group of patients. The reason for this increase was attributed to a compensatory mechanism to restore the perfusion by means of additional blood flow demands of collaterals through the nonharvested ITA and the contralateral intercostal arteries. Nevertheless, the actual mechanism is still unclear.

Cohen's group from Holon, Israel, published a series of $\operatorname{articles}^{13,15,18}$ concerning the effect of skeletonization of ITA grafts on sternal perfusion. They concluded that harvesting pedicled ITA grafts caused acute postoperative ster- nal ischemia, and this was not the case if ITA grafts were skeletonized or semiskeletonized. However, those patients had their postoperative control scans 4 to 9 days after surgical intervention. This huge variation between the timing of control scans in the early postoperative period limits the value of the results. In addition, the 3 groups compared in these studies were not randomized and operated on in the same time period. Our study lacks the skeletonized ITA group but represents the missing chain in the time course of reperfusion clearly in the pedicled ITA group. It is still early to make a final decision, and the effect of skeletonization on sternal perfusion needs to be evaluated by further randomized studies with larger numbers of patents with welldefined time points.

The harvest of arterial conduits with the USS ${ }^{21,24,25}$ has been a relatively novel concept for less than a decade. Concurrently, the effects of ultrasonic dissection on arterial conduits have been evaluated using morphologic and physiologic properties by several authors. ${ }^{23,26,27}$ Lamm and coworkers $^{23}$ randomized 24 consecutive patients into 2 groups: ITA grafts harvested either by means of electrocautery or by means of USS for aortocoronary bypass. They performed a morphologic analysis of endothelium by using a scanning electron microscope and found that the USS 


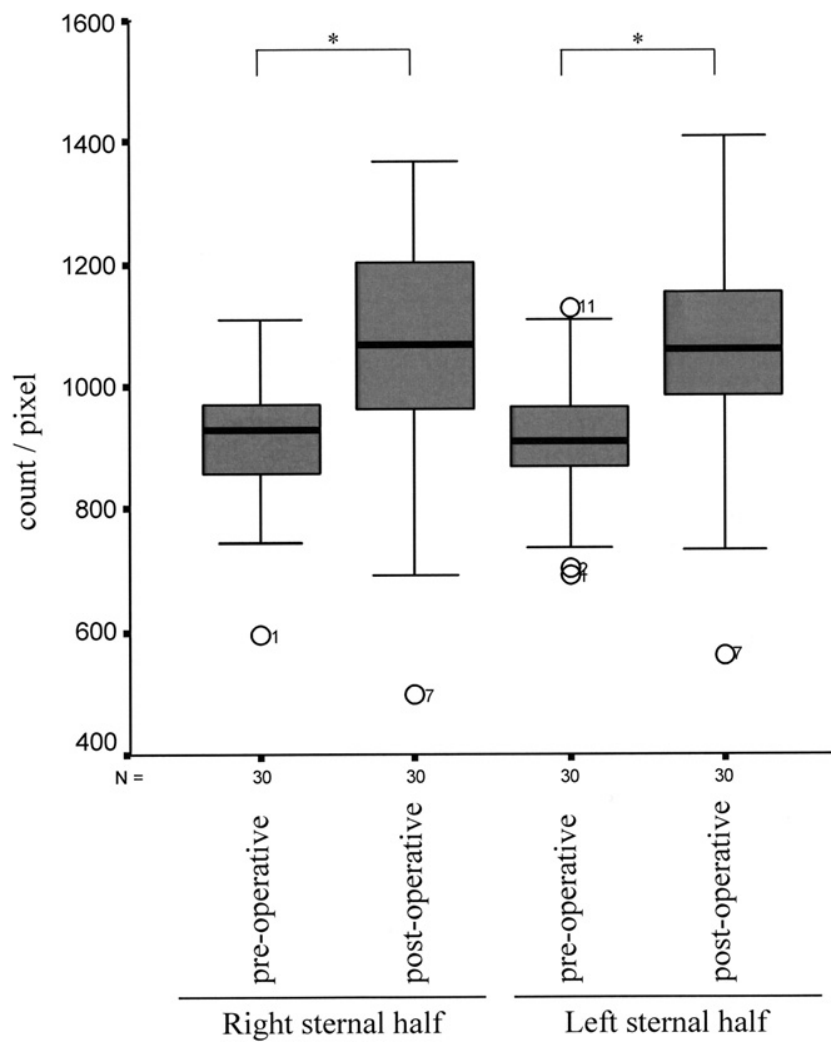

Figure 2. Sternal perfusion for all patients. The data obtained from preoperative and postoperative scintigraphies are shown in box-plot format. Open circles represent the patients' values out of $75 \%$ confines, and numbers represent the corresponding patient. $* P<.05$.

caused less endothelial damage compared with that caused by electrocautery when the ITA pedicle size was less than $0.5 \mathrm{~cm}$. In addition, carbonization damage on the outer layer of all the ITA grafts was detected in the electrocautery group. Recently, Yoshikai and colleagues ${ }^{27}$ reported completely preserved endothelial integrity in ITA specimens skeletonized with a USS in a series of 9 patients, but no comparison between use of a USS and electrocautery was made because of the study design. In contrast, in a randomized study previously published from our clinic, Cikirikcioglu and associates ${ }^{26}$ had found no difference in vasoreactivity and endothelial integrity of the radial arteries harvested by means of either electrocautery or USS use. Nevertheless, flow of alternating current and excessive heat generation caused by electrocautery while operating might have some reversible (ie, vasospasm) or irreversible adverse effects on arterial conduits and on surrounding tissue. Larger areas of coagulation necrosis after dissection of the lung tissue by means of electrocautery were reported before. ${ }^{22}$ Thermal injury created with a USS is much less than
TABLE 3. Postoperative data

\begin{tabular}{|c|c|c|c|}
\hline & $\begin{array}{l}\text { EC group } \\
(n=15)\end{array}$ & $\begin{array}{l}\text { USS group } \\
(\mathbf{n}=15)\end{array}$ & $P$ value \\
\hline Intubation time (h) & $12.2 \pm 4.6$ & $10.9 \pm 4.6$ & .3 \\
\hline Total drainage $(\mathrm{mL})$ & $513.3 \pm 215.9$ & $573.3 \pm 225.9$ & .4 \\
\hline Sternal dehiscence & 1 & 1 & 1.0 \\
\hline \multicolumn{4}{|l|}{ Inotropic support } \\
\hline Dopamine infusion & 5 & 3 & .4 \\
\hline Dobutamine infusion & 1 & 0 & .3 \\
\hline Adrenaline infusion & 3 & 0 & .1 \\
\hline IABP & 1 & 0 & .3 \\
\hline Low cardiac output & 2 & 0 & .1 \\
\hline Arrhythmia & 3 & 4 & .7 \\
\hline Resuscitation & 1 & 0 & .3 \\
\hline ICU stay $(d)$ & $1.1 \pm 0.4$ & $1.1 \pm 0.3$ & .8 \\
\hline $\begin{array}{l}\text { Postoperative hospital } \\
\text { stay (d) }\end{array}$ & $7.2 \pm 0.9$ & $7.3 \pm 1.4$ & .9 \\
\hline
\end{tabular}

EC, Electrocautery; USS, ultrasonic scalpel; $I A B P$, intra-aortic balloon pump; ICU, intensive care unit.

that created with electrocautery, mainly because of different working principles. One would hypothesize that less thermal injury generated while harvesting ITA grafts should cause less coagulation necrosis and thus less microcirculatory deficits on the thoracic wall. Our study, for the first time in the literature, provides the data for sternal perfusion after ultrasonically harvested ITA grafts. The pattern of sternal perfusion after ITA harvest with a USS showed no difference from that of electrocautery, proving the restorage of sternal reperfusion at the end of first week.

Our study has a number of limitations. Two major limitations are the small size of the patient population and the presence of only one time point for scintigraphy during the healing period. More than one postoperative control scintigraphy and a larger population size would have provided more data. Because of the fact that our radioactive investigations were actually not a part of the routine clinical treatment protocol, we preferred to limit the size of the study population and postoperative time points for scintigraphic investigations as they were performed. The small size of the patient population also hinders us from making further analysis on the correlation of sternal dehiscence occurrence and sternal perfusion changes. We also decided not to include the patients who have risk factors (eg, diabetes, malignancy, age older than 75 , and obesity) or bilateral ITA grafting to get the biologic response to use of a USS in comparison with electrocautery. It is obvious that our results cannot account for those high-risk patients.

\section{Conclusions}

Sternal perfusion is restored soon after CABG surgery, probably as a consequence of the healing process, but the source of this reperfusion remains unclear. Harvesting of 
ITA grafts with a USS has no advantage over electrocautery with regard to sternal perfusion in selected patients. We conclude that sternal perfusion is not affected by the method concerning the USS and electrocautery and is restored by the end of first week if the ITA graft is harvested as a pedicled graft in nondiabetic patients. Further studies should be performed in diabetic patients, patients undergoing bilateral ITA harvest, or both to clarify the effect of the USS and the time course of sternal reperfusion, as well as the effects of skeletonization on sternal healing.

We thank Dr Ebru Sezer, Ege University Department of Biochemistry, for her great effort and help in statistics and graphics. This study was performed in Ege University Hospital, Departments of Cardiovascular Surgery and Nuclear Medicine.

\section{References}

1. Green GE. Internal mammary artery to coronary artery anastomosis: three-year experience with 165 patients. Ann Thorac Surg. 1972;14: 260-71.

2. Barner HB, Swartz MT, Mudd JG, Tyras DH. Late patency of the internal mammary artery as a coronary bypass conduit. Ann Thorac Surg. 1982;34:408-12.

3. Grondin CM, Campeau L, Lespérance J, Enjalbert M, Baurossa MG. Comparison of late changes in internal mammary artery and saphenous vein grafts in two consecutive series of patients 10 years after operation. Circulation. 1984;70(suppl 1):208-12.

4. Arnold M. The surgical anatomy of sternal blood supply. J Thorac Cardiovasc Surg. 1972;64:596-610.

5. Seyfer AE, Shriver CD, Miller TR, Graeber GM. Sternal blood flow after median sternotomy and mobilization of the internal mammary arteries. Surgery. 1988;104:899-904.

6. Parish MA, Asai T, Grossi EA, Esposito R, Galloway AC, Colvin SB, et al. The effects of different techniques of internal mammary artery harvesting on sternal blood flow. J Thorac Cardiovasc Surg. 1992; 104:1303-7.

7. Carrier M, Gregoire J, Trone F, Cartier R, Leclere Y, Pelletier LC. Effect of internal mammary dissection on sternal vascularization. Ann Thorac Surg. 1992;53:115-9.

8. Culliford AT, Cunningham JN, Zeff RH, Isom OW, Teiko P, Spencer FC. Sternal and costochondral infections following open heart surgery. J Thorac Cardiovasc Surg. 1976;52:714-25.

9. Palmer JH, Taylor GL. The vascular territories of the anterior chest wall. Br J Plast Surg. 1986;39:287-99.

10. Reid CD, Taylor GL. The vascular territory of the acromiothoracic axis. Br J Plast Surg. 1984;37:194-212.

11. De Jesus RA, Ackland RD. Anatomic study of the collateral blood supply of the sternum. Ann Thorac Surg. 1995;59:163-8.

12. Rivas LF, Hawkins T, Morritt GN, Behl RP, Griffin SC, Brown AH. Radiopharmaceutical uptake as a marker of sternal blood supply fol- lowing internal mammary artery harvesting. Cardiovasc Surg. 1994;2:203-6.

13. Cohen AJ, Lockman J, Lorberboym M, Bder O, Cohen N, Medalion B, et al. Assessment of sternal vascularity with single photon emission computed tomography after harvesting of the internal thoracic artery. J Thorac Cardiovasc Surg. 1999;118:496-502.

14. Korbmacher B, Schmitt HH, Bauer G, Hoffmann M, Vosberg H, Simic $\mathrm{O}$, et al. Change of sternal perfusion following preparation of the internal thoracic artery-a scintigraphical study. Eur J Cardiothorac Surg. 2000;17:58-62.

15. Medalion B, Katz MG, Lorberboym M, Bder O, Schachner A, Cohen AJ. Decreased sternal vascularity after internal thoracic artery harvesting resolves with time: an assessment with single photon emission computed tomography. J Thorac Cardiovasc Surg. 2002;123:508-11.

16. Knobloch K, Lichtenberg A, Pichlmaier M, Mertsching H, Krug A, Klima U, et al. Microcirculation of the sternum following harvesting of the left internal mammary artery. Thorac Cardiovasc Surg. 2003;51: 255-9.

17. Fokin AA, Robicsek F, Fokin A Jr, Anderson JE Jr. Changes in sternal blood flow after different methods of internal thoracic artery harvesting. Thorac Cardiovasc Surg. 2004;52:334-7.

18. Lorberboym M, Medalion B, Bder O, Lockman J, Cohen N, Schahner A, et al. $99 \mathrm{mTc}-\mathrm{MDP}$ bone SPECT for the evaluation of sternal ischaemia following internal mammary artery dissection. Nucl Med Commun. 2002;23:47-52.

19. Athanasiou T, Crossman MC, Asimakopoulos G, Cherian A, Weerasinghe A, Glenville B, et al. Should the internal thoracic artery be skeletonized? Ann Thorac Surg. 2004;77:2238-46.

20. Ronan JW, Perry LA, Barner HB, Sundt TM III. Radial artery harvest: comparison of ultrasonic dissection with standard technique. Ann Thorac Surg. 2000;69:113-4.

21. Posacioglu H, Atay Y, Cetindag B, Saribulbul O, Buket S, Hamulu A. Easy harvesting of radial artery with ultrasonically activated scalpel. Ann Thorac Surg. 1998;65:984-5.

22. Cakan A, Cagirici U, Cikirikcioglu M, Posacioglu H, Veral A. The histological effect of harmonic scalpel and electrocautery in lung resections. An experimental study in a rat model. J Cardiovasc Surg. 2004;45:63-5.

23. Lamm P, Juchem G, Weyrich P, Schütz A, Reichard B. The harmonic scalpel: optimizing the quality of mammary artery bypass grafts. Ann Thorac Surg. 2000;69:1833-5.

24. Isomura T, Suma H, Sato T, Horii T. Use of the harmonic scalpel for harvesting arterial conduits in coronary artery bypass. Eur J Cardiothorac Surg. 1998;14:101-3.

25. Tanemoto K, Kanaoka Y, Murakami T, Kuroki K. Harmonic scalpel in coronary artery bypass surgery. J Cardiovasc Surg (Torino). 1998;39: 493-5.

26. Cikirikcioglu M, Yasa M, Kerry Z, Posacioglu H, Boga M, Yagdi T, et al. The effects of the harmonic scalpel on the vasoreactivity and endothelial integrity of the radial artery: a comparison of two different techniques. J Thorac Cardiovasc Surg. 2001;122:624-6.

27. Yoshikai M, Ito T, Kamohara K, Yunoki J. Endothelial integrity of ultrasonically skeletonized internal thoracic artery: morphological analysis with scanning electron microscopy. Eur J Cardiothorac Surg. 2004;25:208-11. 